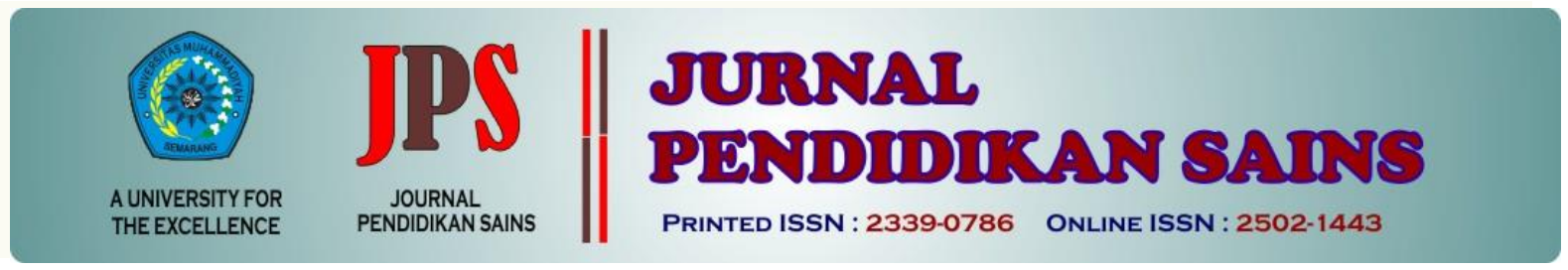

http://jurnal.unimus.ac.id/index.php/JPKIMIA

\title{
ANALISIS MATERI SUBJEK PEMBELAJARAN USAHA DAN ENERGI DENGAN PEDAGOGI MATERI SUBJEK (PMS)
}

\author{
Oleh: \\ Muhamad Ijharudin ${ }^{1}$, Dedi Kuntadi ${ }^{2}$, Rena Denya Agustina ${ }^{3}$, Muhammad Minan Chusni ${ }^{4}$ \\ ${ }^{1}$ PT Kreasi Edulab Indonesia \\ ${ }^{2,3,4}$ Program Studi Pendidikan Fisika, UIN Sunan Gunung Djati Bandung
}

\begin{tabular}{|c|c|c|}
\hline Article hist & & Abstract \\
\hline Submission & : 2018-09-26 & \multirow{5}{*}{$\begin{array}{l}\text { Subject matter as one of the supporting successes of learning, namely } \\
\text { the content, substantive, and syntactic aspects are dominated by the } \\
\text { content aspect, so the ability of the synthetic aspects of students is } \\
\text { lacking. This study aims to analyze aspects of content, substantive, and } \\
\text { syntactic learning of business and energy conducted in class X MIA } 4 \\
\text { MAN } 2 \text { Garut. The study was conducted with a qualitative approach to } \\
\text { discourse analysis research methods. The results of the analysis of the } \\
\text { data obtained in the field resulted in } 64.29 \% \text { aspect of the content, the } \\
\text { substantive aspect of } 28.57 \% \text { and the syntactical aspect of } 7.14 \% \text {. The } \\
\text { results of the study indicate that the content aspect dominates other } \\
\text { aspects. Analysis of subject matter aspects contained in subject matter } \\
\text { pedagogy (PMS) can be used to measure subject matter delivery in } \\
\text { learning activities. }\end{array}$} \\
\hline Revised & $: 20$ & \\
\hline Accepted & $: 2$ & \\
\hline \multicolumn{2}{|l|}{ Keyword: } & \\
\hline \multicolumn{2}{|c|}{$\begin{array}{l}\text { Materi Subjek, Pedagogi, } \\
\text { Usaha dan Energi }\end{array}$} & \\
\hline
\end{tabular}

\section{Pendahuluan}

Materi subjek sebagai salah satu bagian dari proses kegiatan belajar mengajar, merupakan narasumber yang memiliki hak prerogatifnya sebagai tolak ukur nilai kebenaran bagi pengetahuan yang dikembangkan oleh guru dan siswa dalam kegiatan pembelajaran (Siregar: 1999). Materi subjek memiliki wewenang atas kebenaran ilmu sekaligus mewakili disiplin ilmu yang sedang dibahas. Materi subjek dapat dianalisis dengan Pedagogi Materi Subjek (PMS).

PMS merupakan salah satu pendekatan yang dapat menggambarkan atau mengungkapkan kegiatan proses belajar mengajar secara totalitas (Herlanti:2011). PMS melihat kegiatan pembelajaran dari sisi pengajar, peserta didik serta materi subjek yang terlibat pada keduanya. Sehingga dengan PMS dapat terlihat ketersampaian materi subjek itu sendiri pada proses pembelajaran.

Berdasarkan PMS, materi subjek terbagi atas tiga aspek, yakni aspek konten, substantif serta aspek sintaktikal (Rosnita: 2011). Aspek konten merupakan keseluruhan materi fisika yang seharusnya dibahas, dalam penelitian ini yakni materi usaha dan energi Malichatin (2013). Aspek konten memiliki fungsi sebagai unit dasar pengetahuan. Sehingga untuk memiliki pengetahuan yang lebih lanjut yakni aspek substantif dan sintaktikal maka sudah sepatutnya pengetahuan aspek kontennya dimiliki.

Aspek substantif berfungsi sebagai bangunan dari pengetahuan serta aspek

*Corresponding Author:

$\begin{array}{ll}\text { Nama } & : \text { Muhammad Ijharudin } \\ \text { Lembaga } & : \text { PT Kreasi Edulab Indonesia } \\ \text { Email } & : \text { izharmizhar25@gmail.com }\end{array}$


sintaktikal merupakan keterampilan intelektual, yang berperan dalam membangun pengetahuan menggunakan hukum, aturan, teori, dan lainlain untuk menjamin agar bangunan yang dihasilkan mempunyai dasar dan menjamin bangunan tersebut tidak terbantahkan Herlanti (2008). Aspek sintaktikal berkaitan dengan tugas menyederhanakan/merekonstruksi pengetahuan (Rosnita: 2011).

Penelitian ini bertujuan untuk menggambarkan masing-masing aspek materi subjek pada pembelajaran Usaha dan Enerrgi di MAN 2 Garut.

\section{Metode Penelitian}

Penelitian ini dilakukan dengan menggunakan metode deskriptif dan analisis wacana. Metode deskriptif digunakan dengan tujuan untuk mendapatkan informasi dan gambaran mengenai suatu kondisi yang didasarkan pada fakta ilmiah yang didapat saat penelitian (Suharsimi: 2010). Sehingga penelitian ini tidak dimaksudkan untuk menguji suatu hipotesis, melainkan dilakukan untuk mendeskripsikan fakta lapangan.

Sedangkan, metode analisis wacana digunakan atas dasar asumsi terhadap kegiatan proses belajar mengajar merupakan suatu fenomena wacana (Siregar: 1999). Metode ini cocok untuk mengungkapkan kualitas pengajaran guru di kelas (Chandra, Muspiroh, \& Syahrir:2013).

Sebagai metode penelitian, analisis wacana dilakukan dengan prinsip dan metode penelitian serta menuntut pertanggungjawaban ilmiah sebagaimana penelitian ilmiah lainnya (Hamad: 2007). Analisis wacana sebagai suatu metode sangat penting dan andal digunakan untuk memecahkan masalah-masalah ilmu humaniora dan sosial (Arifin, 2012). Oleh karena itu, metode analisis wacana ini dapat menerangkan kandungan isi dari suatu wacana.

Data dalam penelitian ini berupa rekaman video kegiatan proses belajar mengajar di kelas dengan subjek penelitian yaitu guru kelas X MAN 2 yang mengajar di kelas X MIA 4. Instrumen penelitian yang digunakan berupa lembar ceklis yang memuat aspek-aspek materi subjek. Lembar ceklis ini digunakan untuk melihat ketersampaian aspek-aspek materi subjek saat proses pembelajaran berlangsung.

Analisis data dilakukan dengan merubah hasil rekaman video pembelajaran menjadi sebuah teks berupa transkrip, kemudian dilakukan penghalusan terhadap transkrip dengan cara melalui penghapusan dan penyisipan sehingga menjadi teks dasar, penurunan proposisi makro dan mikro, dan selanjutnya dibuat struktur makro. Langkah terakhir, dari struktur makro dianalisis kemunculan masing-masing aspek materi subjek dengan cara menjumlahkan kemunculan aspek materi subjek berdasarkan PMS untuk setiap kategori, kemudian menghitung persentase kemunculan aspek materi subjek berdasarkan PMS.

\section{Hasil Penelitian dan Pembahasan}

Hasil dari struktur makro pada dimensi horizontal berupa topik materi subjek yang sesuai dengan pedagogi guru. Sehingga dapat dianalisis materi subjek yang muncul pada kegiatan pembelajaran tersebut. Berikut hasil analisis terhadap materi subjek yang muncul pada kegiatan pembelajaran:

Tabel 1. Rekapitulasi aspek pada materi subjek

\begin{tabular}{clcc}
\hline No & $\begin{array}{c}\text { Aspek } \\
\text { Materi } \\
\text { subjek }\end{array}$ & $\begin{array}{c}\text { Jumlah } \\
\text { Kemunculan }\end{array}$ & Persentase (\%) \\
\hline 1 & Konten & 14 & 50 \\
\hline 2 & Substantif & 12 & 42,86 \\
\hline 3 & Sintaktikal & 2 & 7,14 \\
\hline & Total & 28 & 100 \\
\hline
\end{tabular}

Terlihat dari Tabel 1, pada kegiatan pembelajaran guru lebih banyak menyampaikan aspek konten dibandingkan aspek yang lain. Aspek konten muncul sebanyak 14 poin sedangkan aspek substantif 12 poin serta aspek sintaktikal 2 poin. Secara persentase, kemunculan masing-masing aspek yakni aspek konten disampaikan sebanyak $50 \%$, substantif sebanyak $42.86 \%$, sedangkan aspek sintaktikal materi subjek usaha dan energi sebesar 7,14\%.

Hasil ini sesuai dengan penelitian yang dilakukan oleh Siahaan (2003) bahwa aspek materi subjek kemunculannya didominasi oleh aspek konten. Tingginya fokus materi subjek yang dilakukan pada aspek konten akan mengakibatkan rendahnya fokus substansi peserta didik (Siahaan: 2003).

Memang benar hal ini dapat terjadi namun aspek konten, substantif dan sintaktikal memiliki porsinya masing-masing. Berikut jumlah masing-masing aspek materi subjek beserta persentase kemunculannya: 
Tabel 2. Kemunculan aspek materi subjek

\begin{tabular}{clccc}
\hline $\mathrm{N}$ & $\begin{array}{c}\text { Aspek } \\
\text { Materi } \\
\text { Subjek }\end{array}$ & $\begin{array}{c}\text { Banyaknya } \\
\text { Indikator }\end{array}$ & $\begin{array}{c}\text { Kemunc } \\
\text { ulan }\end{array}$ & $\begin{array}{c}\text { Persenta } \\
\text { se }(\%)\end{array}$ \\
\hline 1 & Konten & 16 & 14 & $87,5 \%$ \\
\hline 2 & Substantif & 13 & 12 & $92,3 \%$ \\
\hline 3 & Sintaktikal & 6 & 2 & $33,33 \%$ \\
\hline
\end{tabular}

Dari Tabel 2 terlihat kemunculan yang paling tinggi adalah aspek substantif, kemudian aspek konten dan terakhir aspek sintaktikal. Indikator masing-masing aspek tersebut adalah mengemukakan seluruh konsep usaha dan energi untuk aspek konten tercapai sebanyak $87,5 \%$, menghubungkan konsep teoretis dalam persamaan atau pernyataan pada aspek substantif tercapai sebanyak $92,2 \%$ serta proses menemukan konsep teoretis yang baru, atau meminjam konsep yang sudah ada untuk mengembangkan teori baru (abduction) pada aspek sintaktikal sebanyak 33,33\%.

Aspek konten yang berisikan indikator mengenai konsep-konsep fisika yakni usaha dan energi yasng terdiri dari 16 indikator muncul sebanyak 14 indikator atau $87,5 \%$ tersampaikan oleh guru kepada peserta didik. Aspek substantif yang berisikan indikator mengenai hubungan konsep dalam bentuk persamaan tersampaikan $92,3 \%$ atau muncul 12 indikator dari 13 indikator yang ada. Aspek sintaktikal yang memuat indikator penemuan konsep baru dari konsep yang sudah ada hanya tersampaikan sebanyak 2 indikator dari 6 indikator yang ada atau sebesar 33,33\%.

Hal ini menjadikan benar bahwa fokus aspek sintaktikal kurang sehingga kemampuan sintaktikal peserta didik pun kurang karena pengajarnya pun tidak memberikan stimulus dan tidak memberikan informasi awal agar peserta didik memahami itu sehingga untuk aspek sintaktikal sangat kurang sekali (Siahaan: 2003).

\section{Simpulan dan Saran}

Simpulan

Berdasarkan indikator-indikator dari setiap aspek maka diperoleh hasil analisis bahwa kemunculan aspek konten sebanyak $85,71 \%$, aspek substantif sebanyak $100 \%$, dan aspek sintaktikal sebanyak 33,33\%. Memang aspek konten mendominasi munculnya materi subjek namun aspek sintaktikal merupakan aspek yang kemunculannya paling lengkap.
Saran

Dari hasil penelitian ini dapat diberikan saran untuk melakukan analis materi subjek pada materi fisika yang lain agar setiap guru dapat lebih memahami aspek konten, aspek substantive dan aspek sintaktikalnya.

\section{Daftar Pustaka}

Arifin. (2012). Modul Teori dan Aplikasi Analisis Wacana. Singaraja: Program Studi Pendidikan Bahasa Program Pascasarjana Undiksha.

Arikunto. Suharsimi. (2010). Prosedur Penelitian suatu Pendekatan Praktik. Yogyakarta : Rineka Cipta

Chandra, E., Muspiroh, N., \& Syahrir, D. C. (2013). Analisis Pola Wacana Pedagogis Guru Biologi di SMA Negeri 7 Cirebon. Jurnal SCIENTIAE EDUCATIA, 2(April), 99-113.

Hamad, I. (2007). Lebih Dekat dengan Analisis Wacana. Mediator, 8(2).

Herlanti, Y. (2011). Penilaian Proses Belajar Mengajar IPA Di Kelas Melalui Pedagogi Materi Subyek. Education Jornal.

Herlanti, Y., Rustaman, N. Y., \& Setiawan, W. (2008). Strategi Baru dalam Pengolahan Bahan Ajar Ilmu Pengetahuan Alam. Jurnal Edusains, 1(1), 26-38.

Malichatin, H. (2013). Pengembangan Materi Subjek Bagi Mahasiswa Calon Guru Fisika. Jurnal of Innovative Science Education, 2(1), 35-41.

Rosnita. (2011). Standar Pendidikan Untuk Calon Guru Sains: Pedagogi Materi Subjek Sebagai Sarana Pengembangan Pengetahuan Konten Pedagogi Calon Guru. Jurnal Cakrawala Kependidikan, 9(2).

Siahaan, S. M. (2003). Analisis Motif Mengajar Guru dalam Mengajarkan Gerak Melingkar Beraturan dengan Menggunakan Model Fungsi Wacana D'Brazil dan Sinclair. Mimbar Pendidikan, 23(1), 18-24.

Siregar, N. (1999). Pedagogik Materi-Subjek: Dasar-dasar Pengembangan PBM. Bandung: IKIP Bandung. 